\title{
Desain dan Pengembangan Sistem Informasi Administrasi Akademik Dosen (SIAADOS) Dengan Web Dinamis Untuk Peningkatan Karir Dosen Tetap di Universitas Gajayana Malang
}

\author{
Ayudya Mahendaringratry ${ }^{1 *}$, Ellysa Nursanti ${ }^{2}$, Julianus Hutabarat $^{3}$ \\ ${ }^{1}$ Program Studi Teknik Mesin, Universitas Gajayana Malang \\ ${ }^{2,3}$ Program Studi Teknik Industri, Program Pascasarjana, Institut Teknologi Nasional Malang \\ *E-mail: mayudya@gmail.com
}

\begin{abstract}
Abstrak.
Pengelolaan Jabatan Fungsional (JaFung) di Universitas Gajayana (UNIGA) Malang dilakukan dengan manual dimana dokumen pendukung masih disimpan di masing-masing unit kerja dan tidak terarsip dengan benar dan membutuhkan waktu yang lama. Dibutuhkan sebuah sistem yang bisa mengatasi kesulitan penataan aktivitas akademik dosen. Tujuan penelitian ini adalah mendesain dan merancang web dinamis Sistem informasi Administrasi Akademik Dosen (SIAADOS) yang dapat meningkatkan karir dosen di Universitas Gajayana Malang. Dengan SIAADOS maka data akan terintegrasi antar entitas serta adanya transparansi data yang terkontrol. Penelitian ini menggunakan web dinamis dengan merancang Data Flow Diagram (DFD), juga menggunakan tahapan metode Quality Function Deployment (QFD) untuk menetapkan kebutuhan dosen terhadap JaFung menjadi atribut produk jasa, dengan mengumpulkan Voice of Customer $(\mathrm{VoC})$ tahap 1 untuk mencari requirements calon user dan Tahap 2 untuk mencari tingkat kepuasanuser setelah menggunakan SIAADOS. Berdasarkan analisis data tingkat kepuasan user tentang SIAADOS maka disimpulkan bahwa SIAADOS handal dalam memproses pengajuan JaFung dosen di lingkungan UNIGA Malang sehingga akan berdampak pada peningkatan karir dosen yang bersangkutan. Melalui SIAADOS, diperkirakan pengajuan JaFung akan naik sebesar $10 \%$ per tahun.
\end{abstract}

Kata Kunci: Dosen, Jabatan Fungsional, SIAADOS, Quality Function Deployment

\section{Pendahuluan}

Penilaian angka kredit adalah suatu proses penilaian prestasi dosen dilihat dari aktivitasaktivitas yang telah dilakukan dosen berdasarkan pada pedoman penilaian angka kredit Jabatan Fungsional (JaFung) dosen, terdiri atas unsur pendidikan dan pengajaran, unsur penelitian, unsur pengabdian masyarakat dan unsur penunjang Tridharma Perguruan Tinggi [1,2]. Universitas Gajayana (UNIGA) Malang merupakan salah satu lembaga pendidikan formal yang menghasilkan tenaga ahli di bidang ekonomi, teknik, bahasa Inggris, psikologi, ilmu komputer dan manajemen. Saat ini UNIGA Malang mempunyai jumlah dosen sebanyak 83 orang dan masih mempunyai 7 dosen yang memiliki JaFung Tenaga Pengajar. Kondisi ini akan menimbulkan permasalahan manakala Kopertis wilayah VII Jawa Timur melakukan Pengawasan, Pengendalian dan Pembinaan (Wasdalbin) ke PTS di wilayah Jawa Timur. Juga pada saat Borang Akreditasi Prodi maupun Institusi, sehingga perlu dicermati dan segera diatasi agar tidak menimbulkan masalah di kemudian hari. Seharusnya dosen minimal mempunyai jabatan fungsional yaitu asisten ahli dengan kualifikasi pendidikan S2. Sering tertundanya pengajuan JaFung bukan berarti bahwa dosen tersebut tidak produktif dan berkualitas, akan tetapi karena kendala administrasi dalam penentuan kegiatan yang diajukan dan proses perhitungan angka kredit dokumen pelengkap. Dibutuhkan sebuah sistem untuk mengelola pengajuan Jabatan Fungsional (JaFung) dosen agar sesuai standar yang ditetapkan Pemerintah[3,4]. Sistem ini dinamakan Sistem Informasi Administrasi Akademik Dosen (SIAADOS) yang menggunakan web dinamis dimana pengguna bisa mengubah konten dari web tersebut menggunakan browser[5], juga memperhitungkan bagaimana suara konsumen untuk memenuhi standar yang diinginkan dengan menggunakan tahapan metode Quality Function Deployment (QFD) untuk menetapkan kebutuhan dosen terhadap JaFung menjadi atribut produk jasa. 


\section{Metode Penelitian}

Metodologi yang digunakan adalah kombinasi Quality Function Deployment (QFD), web dinamis, serta CMS (Content Management System); yang disimpan dalam MySQL dengan pemrograman PHP (HyperText Preprocessor). Quality Function Deployment (QFD) yang digunakan adalah level 1 untuk melakukan perencanaan produk. Matriks yang digunakan adalah matriks "What's - How's" yang dibuat mengenai suatu gambaran keinginan user (What's), persyaratan tuntutan teknis (How's) dan penilaian kompetitif menggunakan persepsi user[6]. VoC dari calon pengguna yaitu dosen tetap UNIGA Malang untuk didaftar secara rinci kebutuhan user yang nantinya akan menjadi requirement dari sistem ini. VoC diperoleh dengan menyebarkan kuesioner ke dosen UNIGA Malang yang akan menggunakan sistem ini. Dalam penelitian sistem SIAADOS ini peneliti mempertimbangkan angka signifikansi sebesar 0,05 dengan tingkat kepercayaan benar sebesar 95\%. Ukuran populasi real adalah sebesar 83 dosen, dengan mempertimbangkan angka signifikasi 0,05 bukan 1 maka ditentukan menjadi 80 dengan melihat Tabel Krejcie[7], maka ukuran sampel minimal sebesar 66 dosen UNIGA Malanguntuk memperoleh persyaratan user. Dibutuhkan data untuk mentransformasi user demand menjadi design quality, serta detail data dalam merancang spesifikasi desain SIAADOS.Pada saat sistem sudah berjalan maka masih dibutuhkan VoC dari user karena dari sistem ini juga perlu menampilkan informasi mengenai status progres pengajuan JaFung dosen sampai dengan berapa persen, untuk mengetahui rekan dosen prodi yang juga mengajukan JaFung saat itu dengan tujuan sharing informasi dan diskusi kendala, mencari informasi langkah atau prosedur selanjutnya yang harus ditempuh serta pemberitahuan dari pihak pimpinan kepada yang bersangkutan.

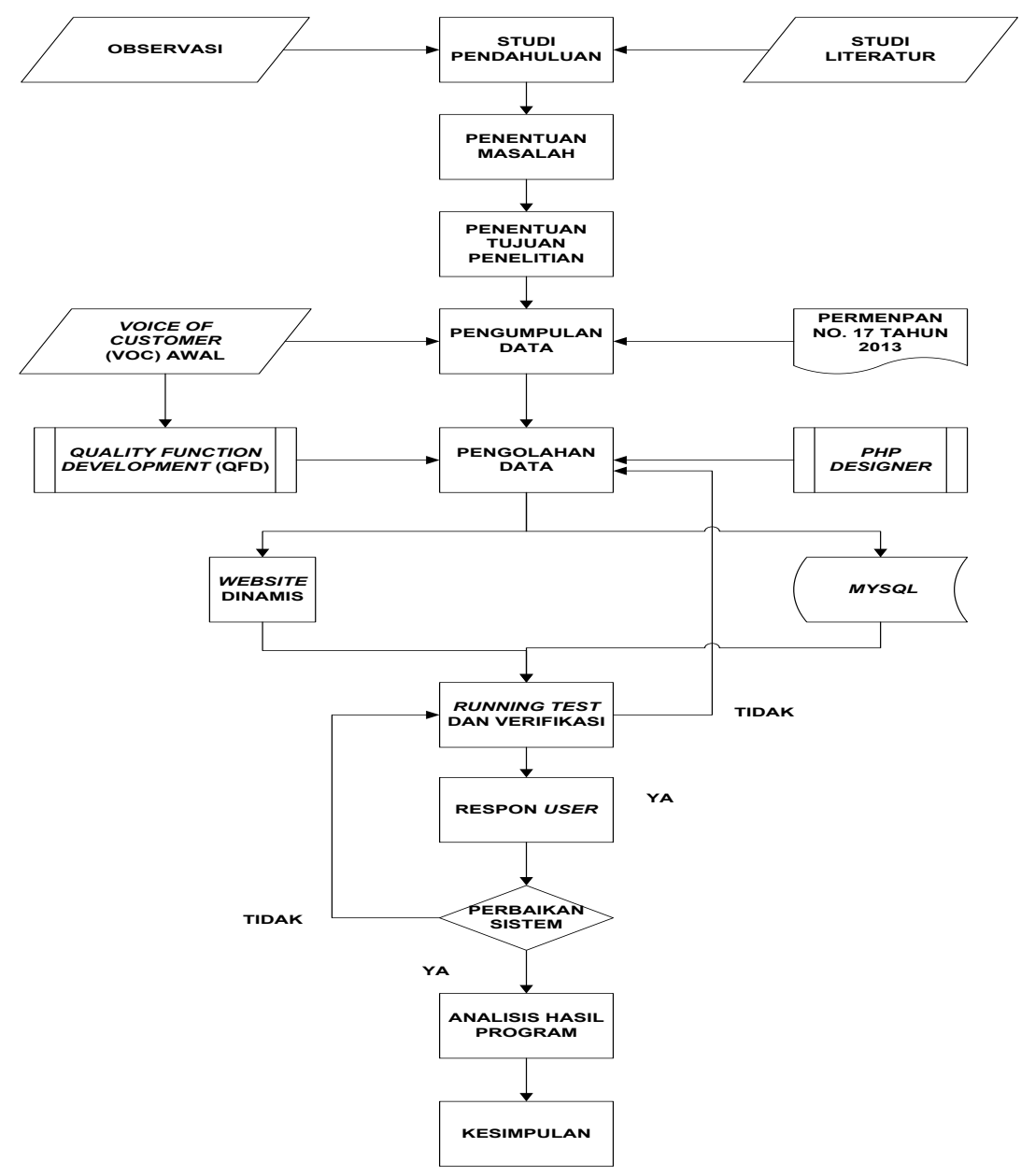

Gambar 1. Diagram Alir Penelitian 
Pada diagram alir Gambar 1, penelitian dimulai dari studi pendahuluan yang didukung dengan observasi dan studi literatur. Kemudian menentukan masalah kurang berkembangnya karir dosen UNIGA Malang yang akan dijadikan subjek penelitian yang nantinya akan dipecahkan dengan sistem yang diterapkan. Langkah selanjutnya adalah menentukan tujuan penelitian yaitu mengetahui tingkat efektifitas Sistem Informasi Administrasi Akademik Dosen (SIAADOS) serta korelasinya dengan peningkatan karir dosen di UNIGA Malang. Setelah menetapkan tujuan penelitian, maka mulai melakukan pengumpulan data, dimulai dari menyusun dan disebar ke responden sebanyak 66 dosen UNIGA Malang. Kemudian mulai merancang bentuk sistem SIAADOS mulai dari merancang Data Flow Diagram (DFD), basis data sistem serta layout program SIAADOS.Dalam Data Flow Diagram ini terbagi menjadi tujuh level user, yaitu administrator, operator, LPPM, Kepegawaian, Dosen, Tim PAK dan Rektor yang dapat mengakses sistem. Rancangan layout yang utama adalah beranda, login, forum dan user interface. Analisa hasil program dilakukan guna mendefinisikan seberapa baik SIM dapat beroperasi pada organisasi yang menerapkannya untuk memperbaiki prestasi di masa mendatang. Evaluasi fungsi SIAADOS dengan meminta respon user setelah menggunakan SIAADOS mengenai kelayakan operasional menilai apakah aplikasi sistem informasi dapat dikerjakan dan berhasil.

\section{Hasil Penelitian dan Pembahasan}

Berikut persyaratan user dan persyaratan teknik yang dibutuhkan dalam HoQpada Tabel 1.

Tabel 1. Persyaratan user dan persyaratan teknik

\begin{tabular}{|c|c|c|c|}
\hline No & Persyaratan User & No & Persyaratan Teknik \\
\hline 1. & $\begin{array}{l}\text { Waktu loading yang cepat agar user mendapat informasi dengan tepat dan } \\
\text { singkat }\end{array}$ & 1. & Requirement Gathering \\
\hline 2. & $\begin{array}{l}\text { Tidak perlu halaman antara yang biasanya ditampilkan sebelum halaman } \\
\text { utama (disebut Splash Page/Intermissiion) }\end{array}$ & 2. & Persiapan Web Server \\
\hline 3. & $\begin{array}{l}\text { Informasi yang berasal dari pimpinan harus jelas dibaca dan pada tempat yang } \\
\text { mudah dijangkau serta jelas terlihat (bagian atas halaman sehingga user dapat } \\
\text { menemukan dengan cepat) }\end{array}$ & 3. & Persiapan Web Editor \\
\hline 4. & $\begin{array}{l}\text { Desain dibuat dengan struktur penempatan konten (header, footer, menu } \\
\text { navigasi dan blok iklan) yang tepat dan mudah dimengerti }\end{array}$ & 4. & $\begin{array}{l}\text { Pemilihan Domain dan } \\
\text { Hosting }\end{array}$ \\
\hline 5. & $\begin{array}{l}\text { Desain konten dibuat sama pada setiap halaman sehingga } \text { user tidak dibuat } \\
\text { bingung akibat menu yang berpindah-pindah }\end{array}$ & 5. & Quick Design \\
\hline 6. & $\begin{array}{l}\text { Pemilihan warna, logo website dan font dibuat sama dengan } \\
\text { www.unigamalang.ac.id sebagai identitas institusi UNIGA Malang }\end{array}$ & 6. & Building Prototype \\
\hline 7. & Tidak perlu ada iklan karena user hanya mencari konten website saja & 7. & $\begin{array}{l}\text { User Testing and } \\
\text { Evaluation of Prototype }\end{array}$ \\
\hline 8. & $\begin{array}{l}\text { Tidak perlu menggunakan link yang terlalu banyak, hanya yang terkait dengan } \\
\text { JaFung yaitu : Kopertis VII Jawa Timur, Simlitabmas, portal } e \text {-journal }\end{array}$ & 8. & Engineer Product \\
\hline 9. & Navigasi website jangan dirubah terlalu mencolok agar situs mudah diingat & 9. & User Practising \\
\hline 10. & $\begin{array}{l}\text { Untuk mengurangi tingkat kesalahan jangan menggunakan link yang tidak } \\
\text { berfungsi (broken link) ataupun halaman yang masih dalam proses pembuatan } \\
\text { (under construction) }\end{array}$ & 10. & $\begin{array}{l}\text { Controlling dan } \\
\text { Maintenance Web }\end{array}$ \\
\hline 11. & Situs web harus kompatibel dengan berbagai perangkat tampilannya (browser) & & \\
\hline 12. & $\begin{array}{l}\text { Halaman web harus bisa dipakai oleh setiap dosen baik yang muda maupun } \\
\text { yang sudah tua }\end{array}$ & & \\
\hline 13. & $\begin{array}{l}\text { Web harus interaktif dengan user sebagai user experience dengan situs web itu } \\
\text { sendiri }\end{array}$ & & \\
\hline 14. & $\begin{array}{l}\text { Agar menggunakan hyperlink untuk membawa user ke topik JaFung mulai } \\
\text { dari lampiran II sampai dengan Form Peer Review serta link yang berbunyi } \\
\text { More info about this, Related Links dan lain-lain }\end{array}$ & & \\
\hline 15. & $\begin{array}{l}\text { Agar menggunakan mekanisme feed back yaitu Comment, Questions, } \\
\text { Pooling/Survey }\end{array}$ & & \\
\hline
\end{tabular}

Setelah semua langkah-langkah mengimplementasikan metode QFD (menyusun matrik HoQ) selesai dilakukan, didapatkan matriks HoQ secara lengkap sebagai berikut pada Gambar 2. 
Jurnal Teknologi dan Manaje

Pascasarjana Institut Teknol

Hubungan Antar Persyaratan Teknik

$\div \quad=$ Hubungan positif kuat, bernilai $(+9)$

$\div \quad=$ Hubungan positif lemah, bernilai $(+3)$

$\mathbf{x x}=$ Hubungan negatif lemah, bernilai $(-3)$

$\mathbf{x}=$ Hubungan negatif kuat, bernilai (-9)

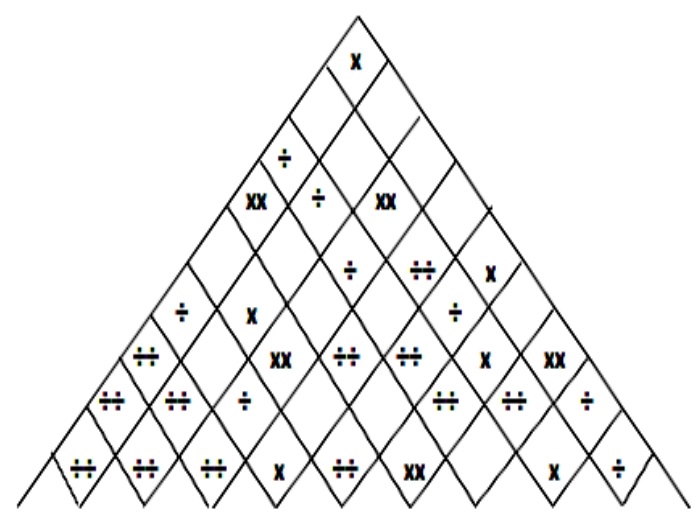

Hubungan Antara Persyaratan User (What) dan

Persyaratan Teknik (How)

Sebuah lingkaran penuh menunjukkan sebuah hubungan yang kuat, bernilai 9

$0=$ Sebuah lingkaran kosong menunjukkan sebuah hubungan medium, bernilai 3

$\Delta=$ Sebuah segitiga menunjukkan sebuah hubungan yang lemah, bernilai 1

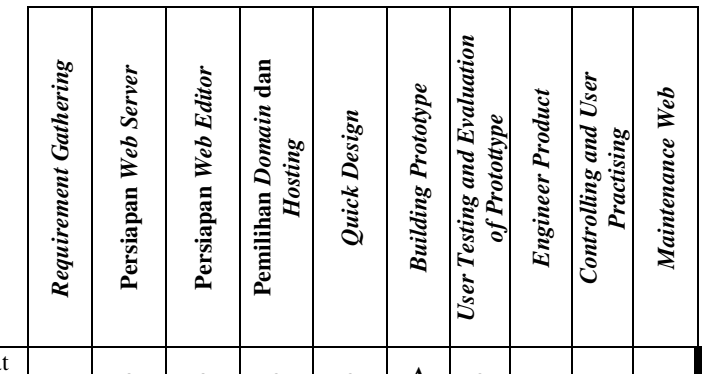

\begin{tabular}{|c|c|c|c|c|c|c|c|c|c|c|c|c|c|c|c|c|c|}
\hline \multicolumn{2}{|c|}{$\begin{array}{l}\text { Waktu loading yang cepat agar user mendapat } \\
\text { informasi dengan tepat dan singkat }\end{array}$} & & $\mathrm{O}$ & $\mathrm{O}$ & $\bullet$ & • & $\Delta$ & $\bullet$ & & & & 1 & 2 & 5 & 4 & $\mathbf{0 , 8}$ & 4 \\
\hline \multicolumn{2}{|c|}{$\begin{array}{l}\text { Tidak perlu halaman antara yang biasanya } \\
\text { ditampilkan sebelum halaman utama (disebut } \\
\text { Splash Page/Intermissiion) }\end{array}$} & $\bullet$ & & $\bullet$ & $\Delta$ & $\mathrm{O}$ & $\Delta$ & $\mathrm{O}$ & & & & 2 & 4 & 4 & 4 & 1,0 & 4 \\
\hline \multicolumn{2}{|c|}{$\begin{array}{l}\text { Informasi yang berasal dari pimpinan harus jelas } \\
\text { dibaca dan pada tempat yang mudah dijangkau } \\
\text { serta jelas terlihat (bagian atas halaman sehingga } \\
\text { user dapat menemukan dengan cepat) }\end{array}$} & $\bullet$ & & $\bullet$ & $\mathrm{O}$ & $\mathrm{O}$ & $\bullet$ & & $\Delta$ & & & 1 & 4 & 5 & 4 & $\mathbf{0 , 8}$ & 4 \\
\hline \multicolumn{2}{|c|}{$\begin{array}{l}\text { Desain dibuat dengan struktur penempatan } \\
\text { konten (header, footer, menu navigasi dan blok } \\
\text { iklan) yang tepat dan mudah dimengerti }\end{array}$} & & $\mathrm{O}$ & $\bullet$ & $\Delta$ & $\bullet$ & $\bullet$ & & $\mathrm{O}$ & $\mathrm{O}$ & & 4 & 4 & 5 & 4 & 0,8 & 4 \\
\hline \multicolumn{2}{|c|}{$\begin{array}{l}\text { Desain konten dibuat sama pada setiap halaman } \\
\text { sehingga user tidak dibuat bingung akibat menu } \\
\text { yang berpindah-pindah }\end{array}$} & & & $\mathrm{O}$ & $\bullet$ & $\bullet$ & $\bullet$ & $\mathrm{O}$ & $\Delta$ & $\Delta$ & & 4 & 3 & 4 & 4 & 1,0 & 4 \\
\hline \multicolumn{2}{|c|}{$\begin{array}{l}\text { Pemilihan warna, logo website dan font dibuat } \\
\text { sama dengan www.unigamalang.ac.id sebagai } \\
\text { identitas institusi UNIGA Malang }\end{array}$} & $\bullet$ & & $\Delta$ & & $\mathrm{O}$ & & & & $\bullet$ & & 4 & 4 & 4 & 4 & 1,0 & 4 \\
\hline \multicolumn{2}{|c|}{$\begin{array}{l}\text { Tidak perlu ada iklan karena } \text { user hanya mencari } \\
\text { konten website saja }\end{array}$} & $\bullet$ & & & & $\mathrm{O}$ & $\mathrm{O}$ & & & $\bullet$ & & 4 & 5 & 4 & 4 & 1,0 & 4 \\
\hline \multicolumn{2}{|c|}{$\begin{array}{l}\text { Tidak perlu menggunakan link yang terlalu } \\
\text { banyak, hanya yang terkait dengan JaFung yaitu: } \\
\text { Kopertis VII Jawa Timur, Simlitabmas, portal } e \text { - } \\
\text { journal }\end{array}$} & & $\bullet$ & $\bullet$ & $\mathrm{O}$ & $\bullet$ & $\Delta$ & $\mathrm{O}$ & & & $\mathrm{O}$ & 1 & 1 & 5 & 4 & $\mathbf{0 , 8}$ & 4 \\
\hline \multicolumn{2}{|c|}{$\begin{array}{l}\text { Navigasi website jangan dirubah terlalu } \\
\text { mencolok agar situs mudah diingat }\end{array}$} & & $\bullet$ & $\bullet$ & & $\Delta$ & & & & & $\mathrm{O}$ & 3 & 4 & 4 & 4 & 1,0 & 4 \\
\hline \multicolumn{2}{|c|}{$\begin{array}{l}\text { Untuk mengurangi tingkat kesalahan jangan } \\
\text { menggunakan link yang tidak berfungsi (broken } \\
\text { link) ataupun halaman yang masih dalam proses } \\
\text { pembuatan (under construction) }\end{array}$} & & $\bullet$ & $\bullet$ & o & o & $\mathrm{O}$ & & & & $\mathrm{O}$ & 3 & 3 & 5 & 4 & $\mathbf{0 , 8}$ & 4 \\
\hline \multicolumn{2}{|c|}{$\begin{array}{l}\text { Situs web harus kompatibel dengan berbagai } \\
\text { perangkat tampilannya (browser) }\end{array}$} & • & & • & & $\bullet$ & $\mathrm{o}$ & o & $\Delta$ & & o & 1 & 3 & 4 & 4 & 1,0 & 4 \\
\hline \multicolumn{2}{|c|}{$\begin{array}{l}\text { Halaman web harus bisa dipakai oleh setiap } \\
\text { dosen baik yang muda maupun yang sudah tua }\end{array}$} & $\bullet$ & & o & & o & & $\bullet$ & & & & 3 & 3 & 3 & 4 & 1,3 & 3,9 \\
\hline \multicolumn{2}{|c|}{$\begin{array}{l}\text { Web harus interaktif dengan user sebagai user } \\
\text { experience dengan situs web itu sendiri }\end{array}$} & • & & & & & $\mathrm{o}$ & $\bullet$ & & $\mathrm{o}$ & $\Delta$ & 3 & 3 & 4 & 4 & 1,0 & 4 \\
\hline \multicolumn{3}{|c|}{$\begin{array}{l}\text { Agar menggunakan hyperlink untuk membawa } \\
\text { user ke topik JaFung mulai dari lampiran II } \\
\text { sampai dengan Form Peer Review serta link yang } \\
\text { berbunyi More info about this, Related Links dan } \\
\text { lain-lain }\end{array}$} & • & • & & o & & $\mathrm{O}$ & & & $\bullet$ & 1 & 1 & 5 & 4 & $\mathbf{0 , 8}$ & 4 \\
\hline \multicolumn{2}{|c|}{$\begin{array}{l}\text { Agar menggunakan mekanisme feed back yaitu } \\
\text { Comment, Questions, Pooling/Survey }\end{array}$} & & $\bullet$ & $\bullet$ & & o & $\mathrm{O}$ & & & $\Delta$ & $\mathrm{o}$ & 1 & 1 & 5 & 4 & 0,8 & 4 \\
\hline \multirow{2}{*}{$\begin{array}{c}\text { Penilaian Kompetitor } \\
\text { Teknik }\end{array}$} & Benchmark X & 2 & 3 & 2 & 1 & 3 & 3 & 4 & 2 & 1 & 1 & \multirow{2}{*}{ 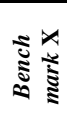 } & \multirow{2}{*}{ 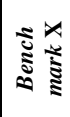 } & \multirow{6}{*}{ 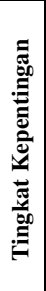 } & \multirow{6}{*}{ 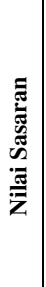 } & \multirow{6}{*}{ 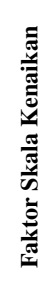 } & \multirow{6}{*}{$\begin{array}{l}\text { 三 } \\
\frac{0}{0} \\
\frac{0}{4} \\
\frac{0}{0} \\
0\end{array}$} \\
\hline & Benchmark X & 2 & 4 & 2 & 2 & 3 & 3 & 4 & 4 & 4 & 4 & & & & & & \\
\hline Derajat Kes & & 3 & 3 & 4 & 4 & 4 & 3 & 4 & 3 & 4 & 3 & \multirow{4}{*}{\multicolumn{2}{|c|}{ 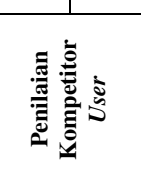 }} & & & & \\
\hline Nilai Sasa & & 2 & 4 & 4 & 3 & 5 & 5 & 3 & 4 & 3 & 3 & & & & & & \\
\hline Bobot Abs & & $\begin{array}{c}15 \\
3\end{array}$ & 364 & 116 & 280 & 135 & $\begin{array}{c}18 \\
9\end{array}$ & 84 & 18 & $\begin{array}{c}10 \\
4\end{array}$ & 75 & & & & & & \\
\hline Bobot Re & & $\begin{array}{c}11 \\
90 \\
7\end{array}$ & 7803 & $\begin{array}{c}3312 \\
4\end{array}$ & 3364 & $\begin{array}{c}1960 \\
0\end{array}$ & $\begin{array}{l}60 \\
75\end{array}$ & 28 & $\begin{array}{c}10 \\
8\end{array}$ & $\begin{array}{l}27 \\
04\end{array}$ & $\begin{array}{c}187 \\
5\end{array}$ & & & & & & \\
\hline
\end{tabular}

Gambar 2. House of Quality SIAADOS 
Berikut desain layout dari web dinamis SIAADOS pada Gambar 3 dan Gambar 4.

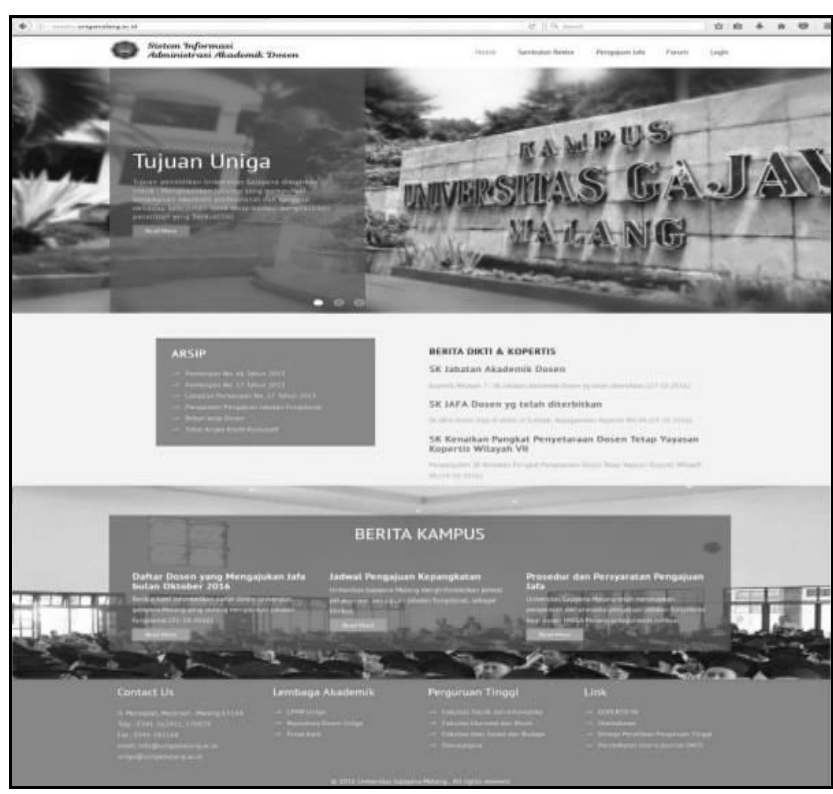

Gambar 3. Beranda

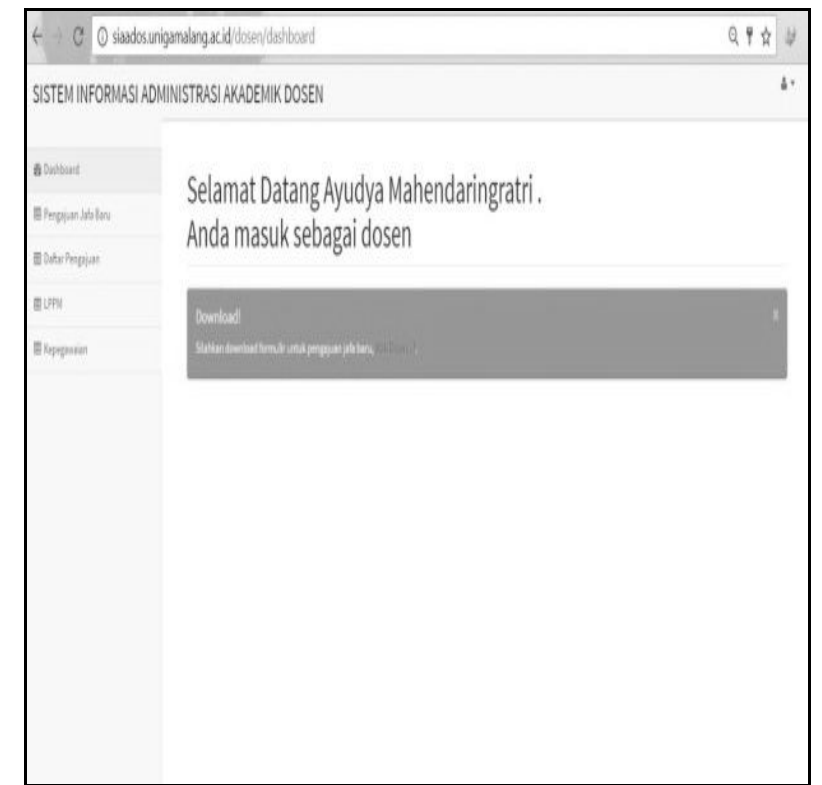

Gambar 4. User Interface

Pada Gambar 3, beranda merupakan halaman awal setelah user mengetikkan alamat url yaitu SIAADOS.unigamalang.ac.id. Dalam beranda menginformasikan antara lain visi, misi, tujuan dan akreditasi institusi; instruksi cara upload pengajuan JaFung SIAADOS UNIGA Malang, arsip kebutuhan pengajuan JaFung, berita Dikti dan Kopertis, berita kampus, link yang terkait JaFung. Pada Gambar 4 yaitu user interface, setelah user berhasil login masuk maka dapat mengakses sesuai haknya. Bila ingin melihat berhasil tidaknya pengajuan maka dapat melihat daftar pengajuan yang tersedia. Daftar ini dapat menampilkan progress dosen yang bersangkutan serta siapa saja yang mengajukan JaFung. Langkah selanjutnya adalah mencari tingkat kepuasan user terhadap SIAADOS, yaitu dengan menggunakan skala likert. Kuesioner disebar sebanyak 66 dosen UNIGA Malang untuk memperoleh tingkat respon user terhadap SIAADOS. Untuk mendapatkan hasil interpretasi, terlebih dahulu dicari skor tertinggi (Y) untuk item penilaian dengan rumus sebagai berikut :

$\mathrm{Y}=$ Skor tertinggi likert dikali jumlah responden (skor tertinggi 5)

$$
=5 \times 66=330
$$

Penilaian interpretasi responden terhadap SIAADOS yang diinginkan adalah nilai yang dihasilkan dengan menggunakan rumus Index :

Rumus Index $(\%)=\frac{\text { Total Score }}{\mathrm{Y}} \times 100 \%$

Kemudian dilihat dari hasil indeks kepuasan, dibagi menjadi beberapa skala tingkat kepuasan, yaitu :

Tabel 2. Tabel Skala Kepuasan Pengguna[8]

\begin{tabular}{|c|c|c|l|}
\hline Bobot & Skor/Angka & Kriteria & \multicolumn{1}{|c|}{ Keterangan } \\
\hline $1=0,0-1,0$ & $0 \%-20 \%$ & STP & Sangat Tidak Puas \\
\hline $2=1,0-2,0$ & $20 \%-40 \%$ & TP & Tidak Puas \\
\hline $3=2,0-3,0$ & $40 \%-60 \%$ & CP & Cukup Puas \\
\hline $4=3,0-4,0$ & $60 \%-80 \%$ & P & Puas \\
\hline $5=4,0-5,0$ & $80 \%-100 \%$ & SP & Sangat Puas \\
\hline
\end{tabular}

Berdasarkan hasil kuesioner dapat disimpulkan bahwa pengguna SIAADOS yaitu dosen di lingkungan UNIGA Malang tergolong puas dimana derajat tingkat loyalitas berjumlah $1.135,77 \%$ dibagi dengan jumlah kriteria kebutuhan atau tingkat kebutuhan yaitu 15, sehingga didapat hasil ratarata $75,72 \%$ dengan bobot 4 yaitu skor/angka $60 \%-80 \%$. 


\section{Kesimpulan}

SIAADOS mampu membantu proses pengajuan JaFung dosen di lingkungan UNIGA Malang sehingga akan berdampak pada peningkatan karir dosen yang bersangkutan. SIAADOS memiliki keunggulan antara lain memberi informasi mengenai status progres pengajuan JaFung dosen, memberi informasi rekan dosen prodi mana saja yang juga mengajukan JaFung saat itu dengan tujuan sharing informasi dan diskusi kendala, adanya pemberitahuan dari pihak pimpinan ke yang bersangkutan, misalnya informasi jadwal, informasi aturan terbaru, dan sebagainya. Dengan adanya SIAADOS, diperkirakan pengajuan JaFung akan naik sebesar $20 \%$ per 2 tahun (berkala) atau sekitar $10 \%$ per tahun. Penelitian ini dapat dikembangkan lebih lanjut dengan mengembangkan sistem SIAADOS untuk lebih user friendly khususnya memperbesar field-field yang ada pada web editor sehingga mampu menjadi decision support system sampai pada tahap penilaian Tim PAK, user hanya menjadi source sistem kepakaran dalam setiap siklus penilaiannya.

\section{Daftar Referensi}

[1] Kementrian Riset, Teknologi dan Pendidikan Tinggi, Sistem Penilaian Angka Kredit Dosen (2016). [Online]. Available: http://pak.dikti.go.id/portal/

[2] Setiaji, Hari \& Kurniawan, Rahardian, Sistem Informasi Penelitian dan Pengabdian Dosen Guna Otomatisasi Penentuan Angka Kredit Dosen dan Mendukung Aktivitas Tridharma Perguruan Tinggi, Seminar Nasional Aplikasi Teknologi Informasi (SNATI) 2011, Yogyakarta, 17-18 Juni 2011, h. E92 - E98, 2011.

[3] Peraturan Menteri Pendayagunaan Aparatur Negara dan Reformasi Birokrasi Nomor: 17 Tahun 2013 tentang Jabatan Fungsional Dosen dan Angka Kreditnya.

[4] Peraturan Menteri Pendayagunaan Aparatur Negara dan Reformasi Birokrasi Republik Indonesia Nomor 46 Tahun 2013 tentang Perubahan Atas Peraturan Menteri Pendayagunaan Aparatur Negara dan Reformasi Birokrasi Nomor 17 Tahun 2013 Tentang Jabatan Fungsional Dosen dan Angka Kreditnya.

[5] Nasrul Firdaus, Banni Satria Andoko \& Evy Sophia, Desain dan Implementasi Sistem Informasi Pengajuan Jabatan Fungsional Akademik Dosen Berbasis Web Pada STMIK PPKIA Pradnya Paramita Malang, Jurnal Dinamika DotCom Vol. 5 No. 1, h.80-91, 2014.

[6] Bernal, Luis, dkk, Quality Function Deployment (QFD) for Service - A Handbook, Jerman: Universitas Leipzig, 2009.

[7] Sekaran, Uma, Metodologi Penelitian Untuk Bisnis. Jakarta: Salemba Empat, 2006.

[8] Gulo, Ferlianus, Penerapan Metode Quality Function Deployment Dalam Melihat Kepuasan Pengguna Air Minum Isi Ulang (Studi Kasus: UD Buana Water Kec. Medan Johor), Majalah Ilmiah Informasi dan Teknologi Ilmiah, Vol. V No. 1, Januari 2015, ISSN: 2339-210X, h.160-165, 2015 . 